\title{
Interoperability Optimisation for Shared Equity Housing Model development and FTB homeownership in the UK
}

\section{Abstract}

Purpose - This paper assessed financial interoperability implications associated with First Time Buyers (FTB) in housing development and the role of the Community Land Trust Shared Equity Housing Model (CLT SEHM).

Design/Methodology/Approach - The Interoperability optimisation process adopted by this study involved triangulated findings from literature, semi-structured interviews and questionnaire surveys. The text analysis of interview responses was actualised with Nvivo 9.0. This process informed the validation of themes through a questionnaire survey (purposive sampling), of which findings were subsequently analysed with statistical methods including binary logistic regression to validate interoperability rational and implications.

Findings - The study identified positive financial interoperability outcomes for a successful synergy between the CLT SEHM and FTBs. From the analysis, there were sustainable results for average income multiple and property transfer/resale value for the CLT SEHM compared to conventional models. However, for the most at risk FTB groups, recommendations included increased concessions for CLT SEHM developments to incentivise bespoke rent purchase hybrid schemes.

Originality/value - This research provided a good starting point for achieving improved level of efficiency necessary for the introduction of emerging/renewed alternative housing models into mainstream operational capabilities in housing and local development policies.

Keywords - UK Housing Development, First Time Buyers (FTB), Interoperability, Community Land Trust, Shared Equity Housing Model, Binary Logistic Regression model 


\section{Introduction}

\section{Interoperability in housing delivery/development}

Due to the faster growing housing rental price and cost of ownership in the UK compared to income (Office of National Statistics, 2014; National Audit Office, 2017), traditional LCHO (Low Cost Housing Ownership) schemes have struggled to cater for the FTB (First Time Buyer) demography. Out of necessity, there is the need to explore renewed homeownership models that could help alleviate shortages among this group. The Community Land Trust Shared Equity Housing Model (CLT SEHM) has been touted as a delivery vehicle that could help tackle inherent problems; moreover, research has identified the FTB as an adaptable group for this model (CFS, 2009). Regardless, the CLT SEHM is underrepresented in affordable housing supply to both this group and the UK in general (Mayor of London 2004; Clark, 2012). Existing research has studied profiles of the FTB and their responsiveness to traditional LCHO schemes, however not much has been done in regards to end user/beneficiary (financial) interoperability with the CLT SEHM. On this note the study sought to investigate associated issues, limitations and barriers that are hampering synergy between the FTB and CLT SEHM as a housing delivery vehicle. The study adopted an interoperability development and optimisation approach; in a bid to improve efficiency in the adoption of housing delivery models that take into consideration end user/population/model limitations during project development and management.

Interoperability from this research context connotes a housing system/model's ability to successfully deliver intended housing goals to a target community or population. According to European Committee for Standardisation (2014) interoperability aims at addressing the requirements of the user community by making services available, easily identifiable, accessible and user oriented. Interoperability therefore ensures the model/system and its targeted adopters work together (inter-operate) successfully by ensuring barriers in this context are addressed to ensure a seamless interaction between end users and the housing delivery vehicle/model/scheme. A domain in this instance is a community, perhaps demography with its subjective nuances which are bound by common goals, peculiarities and problems from a FTB context. On a broader scale this could include legacy, healthcare and insurance applications (Sartipi and Dehmoobad, 2008).

The CLT SEHM although not an entirely conventional housing delivery model, it does have a long history in the UK. However, Mayor of London (2004); Clark (2012) identified that it has occupied a restricted space outside of the mainstream, squeezed out by municipal and voluntary provision. In the context of 'mainstream'/widely accepted housing delivery models, the CLT SEHM is an emerging solution with a demonstrable need to better interoperate with housing seekers and the sector as a whole. This necessity is partly due to the limited effectiveness of traditional models towards achieving intended goals as reviewed in subsequent sections.

\section{Literature Review}

\subsection{An assessment of Affordable Housing Schemes and the FTB}

Traditional affordable housing ownership schemes have gone through several phases with varying degrees of success. In 2014, the UK government introduced the Help to Buy (HTB) scheme as a route towards homeownership in the form of equity loans to assist both FTBs and 
home movers onto the new-build ownership ladder. With an allowed limit of housing purchase prices up to $£ 600,000$, the model mandates beneficiary contribution of at least $5 \%$ of the property price as deposit backed by government loans of $20 \%$, while a mortgage of up to $75 \%$ covers the remaining the cost (National Audit Office, 2014); (CML, 2017).

This scheme however has not been without its criticism. From an interoperability perspective, reports implied that the delivery model the scheme employs appears to be falling short of its goals in respect to the target beneficiaries and the overall affordable housing sector. For example, the International Monetary Fund (IMF) raised concerns on the effect of the scheme on inflation of housing prices, which reduces long and short term affordability for FTBs. On the housing supply side, the scheme intended to stimulate new building, however, these outcome might be farfetched because rather than increasing housing supply, prices are actually skyrocketing causing a destabilising effect on the housing market (Office of Budget Responsibility, 2013, pp. 42). Going by the fact that home building has shown little or no consistent growth in England (National Audit Office, 2017) (Fig 1), recommendations include policies favouring a shift towards relaxation of planning laws and reduction of Local Authority (LA) charges on developers to ease/incentivise the building of new homes (Institute of Directors, 2013).

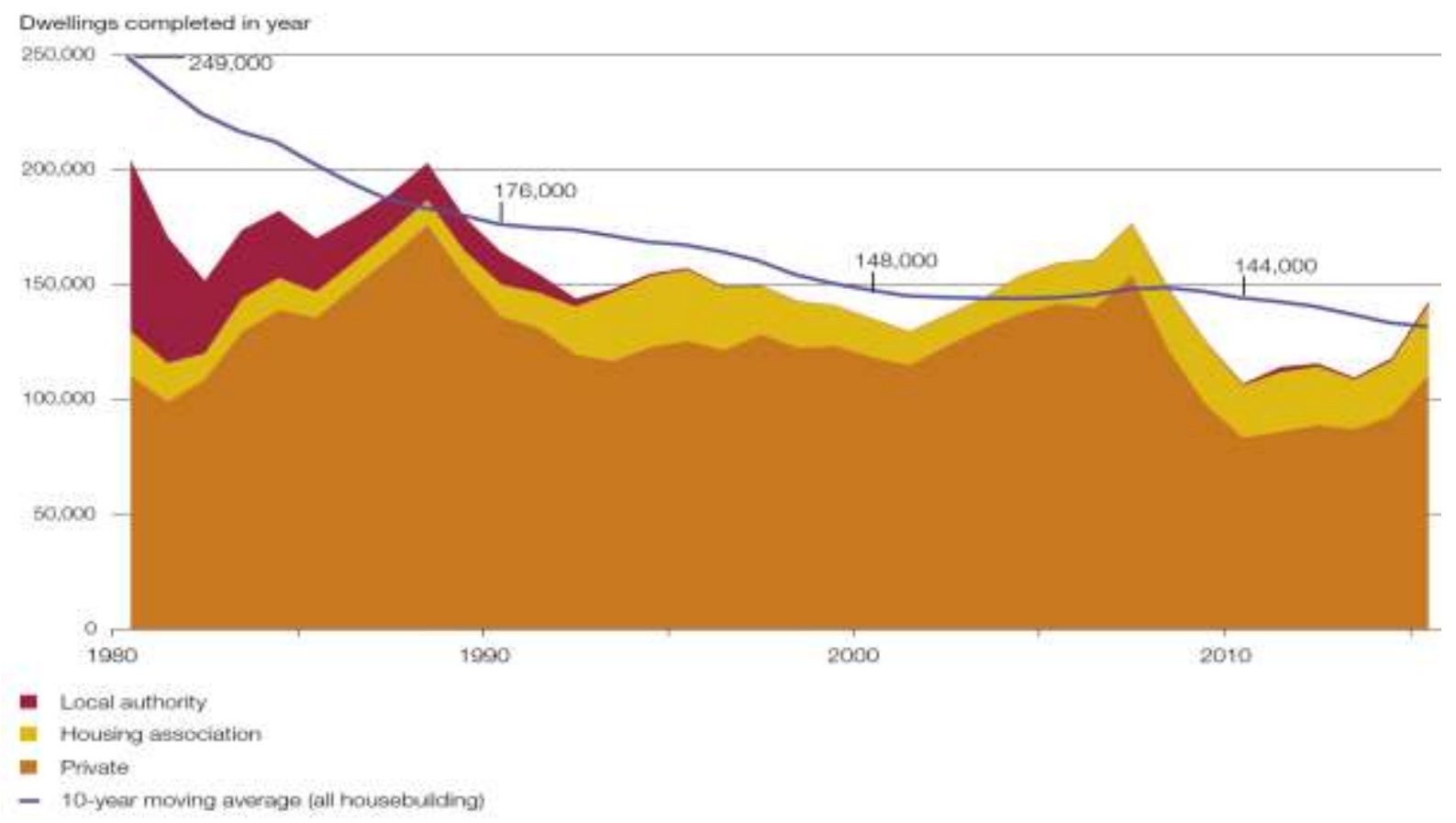

Fig 1: New homes completed in England, 1980 to 2012 (National Audit Office, 2017).

\begin{tabular}{llllll} 
Thousands & $\mathbf{1 9 8 0}$ & $\mathbf{1 9 9 0}$ & $\mathbf{2 0 0 0}$ & $\mathbf{2 0 1 0}$ & $\mathbf{2 0 1 5}$ \\
\hline Private & 110 & 136 & 118 & 83 & 111 \\
\hline Housing Association & 19 & 14 & 17 & 23 & 30 \\
\hline Local Authority & 75 & 14 & 0 & 1 & 2
\end{tabular}

Table 1: Breakdown of new homes completed in England, 1980 to 2012 (National Audit Office, 2017).

On a more optimistic note, the National Audit Office (NAO) concluded that the Help to Buy equity loans model is having a positive effect on mortgage finance in terms of accessibility and 
affordability particularly to FTBs (National Audit Office, 2014). This position however appears not to have taken into consideration the long term effects on the housing market, as the Royal Institution of Chartered Surveyors (RICS) called for caution regarding the possibility of the creation of another housing bubble financed by household debt (RICS, 2014; Dolphin, 2013). Moreover, National Audit Office (2014) analysis found out that when the equity loan is added to the amount of the mortgage, the average income-to-housing debt ratio is 1:4.4. However, about a fifth of borrowers owe at a highly unsustainable level of at least 5.3 times their income (Figure 2). Therefore, lower-income households using the scheme have higher average debt in relation to their income compared to higher-income households which corroborates RICS, (2014); Dolphin (2014)'s position on the scheme's possible complicity in another housing bubble. Moreover, Social housing rents have also increased faster than earnings across the board, i.e. the 25 th percentile of full-time earnings increased by $34 \%$. In contrast, rents for local authority properties increased by $79 \%$ and rents for housing association properties increased by $72 \%$ over the same period (Appendix A) (National Audit Office, Housing in England: Overview, 2017).

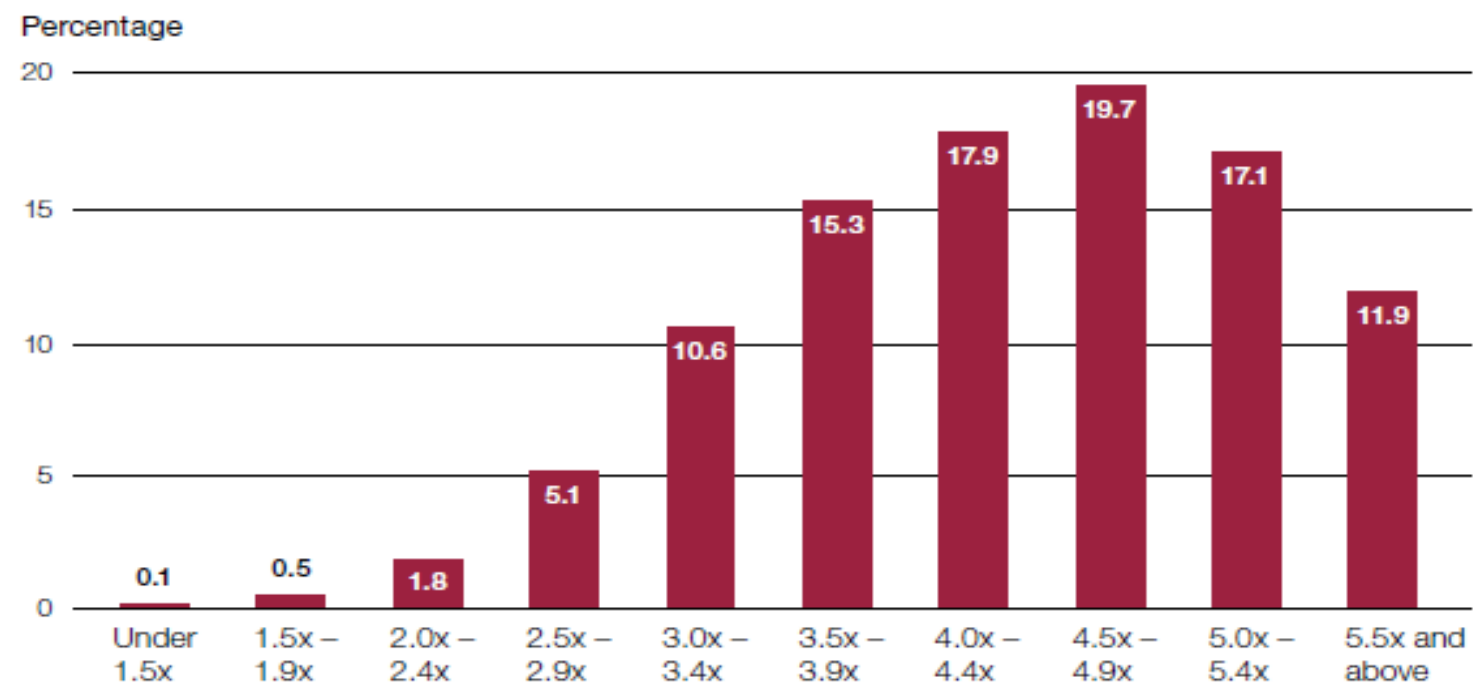

Fig 2: Ratio of total mortgage and equity loan borrowing to household income in the UK (National Audit Office, 2014)

Considering previous schemes, Jones (2011) for example disagreed on the success of First to Buy, arguing that the it had an insignificant impact on problems faced by the vast majority of FTBs, partly because it was exclusively for new-build properties. Moreover, lending favoured only a select group of FTBs which represented a little fraction of the overall number of the most at risk groups. How does the CLT SEHM now fit into all of these? The next section sheds more light into these frontiers and more.

\subsection{The CLT SEHM and FTB: Benchmarks and associated financial interoperability issues}

Attempts to statutorily qualify the CLT (Community Land Trust) include that of a report by Community and Local Governments (2008) which sees the CLT as a local communitycontrolled organisation set up to own; manage land and other assets in perpetuity for the benefit of the community. These assets could include affordable housing, workspaces, agricultural facilities, commercial outlets, or community facilities. The shared Equity Housing Model structure is usually designed to ensure that the CLT provides permanently affordable housing 
within the industry's statutory confines. This involves the adoption of a form of rental and shared equity model that enables beneficiaries to build up just enough equity for a future part purchase, but not to the extent that it hampers the benefits of future tenants. Hence, a significant portion of the equity growth remains with the CLT, thus keeping the houses affordable in perpetuity (Paterson and Dunn, 2009). As tenable as this structure might appear from a viable affordable housing development perspective, the CLT alongside other trusts and cooperative structures are largely underrepresented in the UK's housing stock (Birchall, 2004; Clark, 2012; BSHF, 2016).

First Time Buyers (FTBs) are apparently underrepresented in housing ownership due to huge deposits involved in securing Low Cost Housing Ownership Scheme (LCHOS) options according to Poon and Garratt, (2012). Also, they are not considered as priority when it comes to housing needs, hence are less likely to be able to access public or social housing (CLT, 2008; Coughlan et al, 2011). In the light of LCHOS not effectively living up to expectations for the FTB demography (see earlier section); Monk and Whitehead (2010) recommended that more opportunities should be given to new approaches that would rely less on direct traditional models of public subsidy to help people into home ownership. One of such is the CLT SEHM model, which existing research indicates that the FTBs are an adaptable group for this model (CFS, 2009). However, the CLT SEHM is underrepresented in affordable housing supply to this demography, despite research suggesting that these alternatives are outperforming traditional LCHOS options in affordability and housing satisfaction surveys. Moreover, it is also purported to combat possible price inflation by keeping housing affordable in perpetuity even during ownership transfer or resale (CFS, 2009).

Compared to the perpetual affordability argument, the CLT SEHM appears more sustainable, particularly when IPPR (2014) analysis of the rapidly inflating property prices is put into consideration. This is further buttressed by Office of National Statistics (2014) house price index for the UK (Appendix B) and a United States (US) case study of the Burlington Community Land Trust in which resale data showed both retention of affordability on resale and a controlled substantial increase in value 14yrs later in comparison to open market price (Davis and Demetrowitz, 2003). In this study's context, the aforementioned CLT SEHM attributes thus appear to have the ability to mitigate expressed Office of Budget Responsibility (2013); IPPR (2014)'s concerns in regard to the recent Help to Buy schemes. Amidst the laudable benefits and the need to accord the CLT SEHM a greater role alongside traditional ones, the interoperability of the CLT SEHM does require further research due to both its structure and how it fits in with FTB peculiarities.

FTBs are seen as crucial facilitators in the housing market (Smith et al., 2005; Andrew, 2004). However, the issue of unclear pathways into homeownership creates a hazy understanding of who FTBs actually are. Cases like households moving into homeownership or perhaps people returning after renting for a while are examples of the existing ambiguity in defining FTBs (Wallace and Jones, 2009). Faced with a lack of consensus in defining who potential FTBs are statistically, research seems to point in the direction of the 'under 25' age group. In general they are seen as those aiming to get on the homeownership ladder, hindered by the fact that they have experienced the highest rate of reduction in homeownership since 2001 (Wallace and Jones, 2009). More recent data also indicate a continuous rise in the average age of FTBs. According to data collated by Council of Mortgage Lenders (CML), 26\% of FTBs are aged over 35, with a relatively higher and stable average age of 29 (CML, 2013). In reference to income to house price ratio earlier mentioned in (Fig 2), indications are that the Help to Buy from previous mortgage surveys reveal an unsustainable level that ranges from a year 2015 
trending average of at least 3.0 (Fig 3) (ratio of mortgage advance to income) to 5.3 FTB gross house price to income ratio (CML, 2008a; National Audit Office, 2017). Therefore, benchmarking income levels among home seekers interested in the CLT SEHM is deemed crucial by this research to assess the interoperability of the relationship.

Notes

1. Deposit as a percentage of purchase price is calculated for each case and then averaged for all first-time buyers.

2. Ratio of mortgage advance to income is calculated by dividing the average mortgage advance paid to firsttime buyers by the average income for first-time buyers

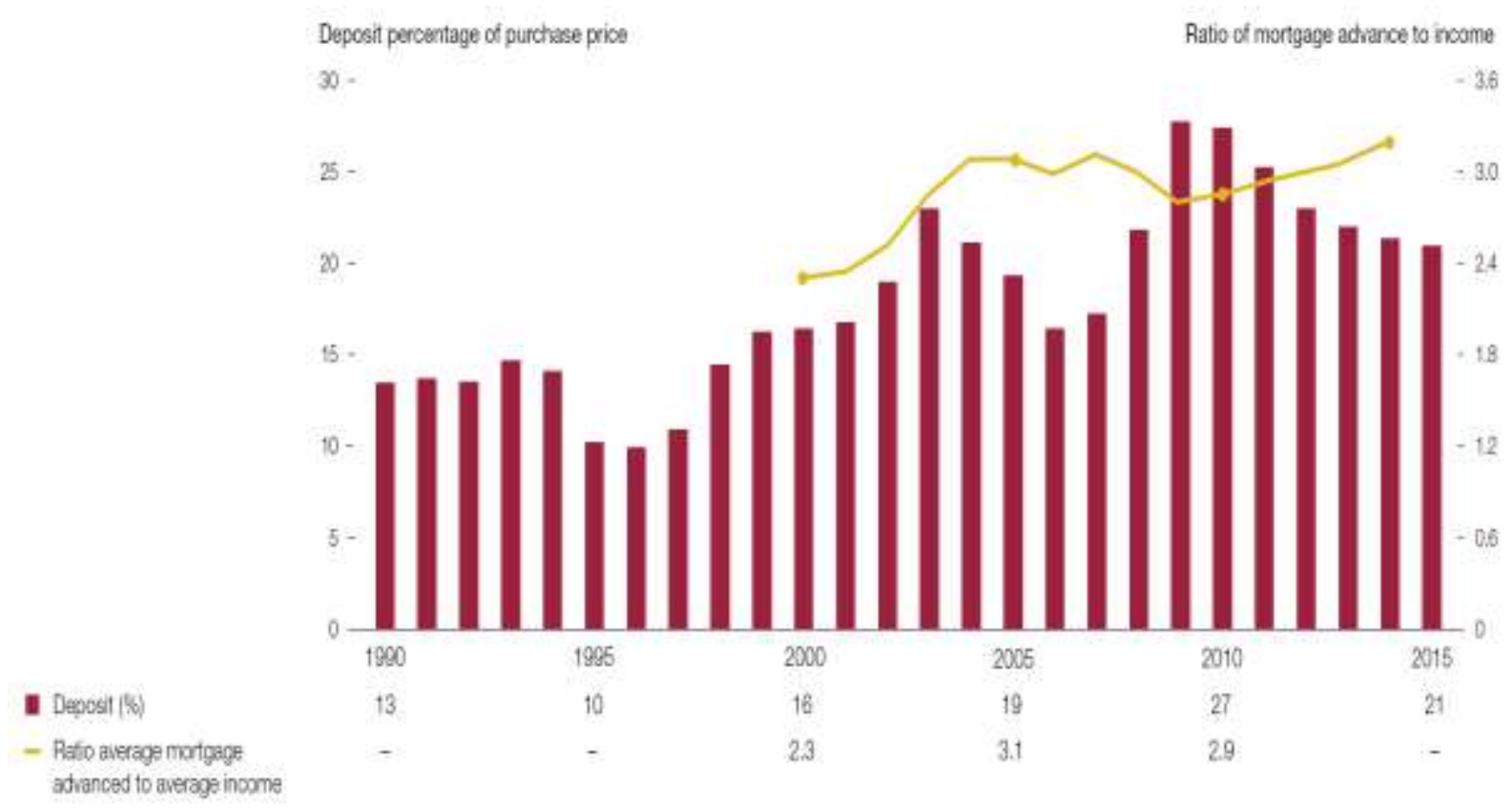

Fig 3: Affordability for first-time buyers - 1990 to 2014 in the UK (National Audit Office, Housing in England: Overview, 2017).

In order to tackle other financial interoperability inconsistences, the study sought to establish the relevance of housing finance problems among population groups that might be interested in the CLT SEHM as a pathway to homeownership. Literature attributed the cause of shortage of suitable affordable and secured housing among FTBs to the peculiarity of their income category, which is considered insufficient to raise large enough mortgage. This is partly due to the high mandatory deposit required on the open market (Paterson, 2010). This view is supported by statistics which reveal a steady increment in required average deposit on FTB targeted homes in England, i.e. more FTBs have to pay increasingly larger deposits for traditional housing schemes as shown in (CML, 2013). Therefore, payment difficulties alongside other finance problems might hamper interest in the CLT SEHM option.

Statistics showed that 25 million households were present in the UK; just less than $1 \%$ of this figure represented people buying a house for the first time (CML, 2011; Asthana and Dyer, 2011). Furthermore, just 37 per cent of all mortgages were approved for FTBs, coupled with a fluctuating decline on the number of loans approved from 2007 onwards (Fig 4) (CML, 2017). Fluctuating improvements on this trend might be due to effects of the Help to Buy scheme 
amidst the threat of potential property market destabilisation as earlier mentioned, particularly from 2013 till date.

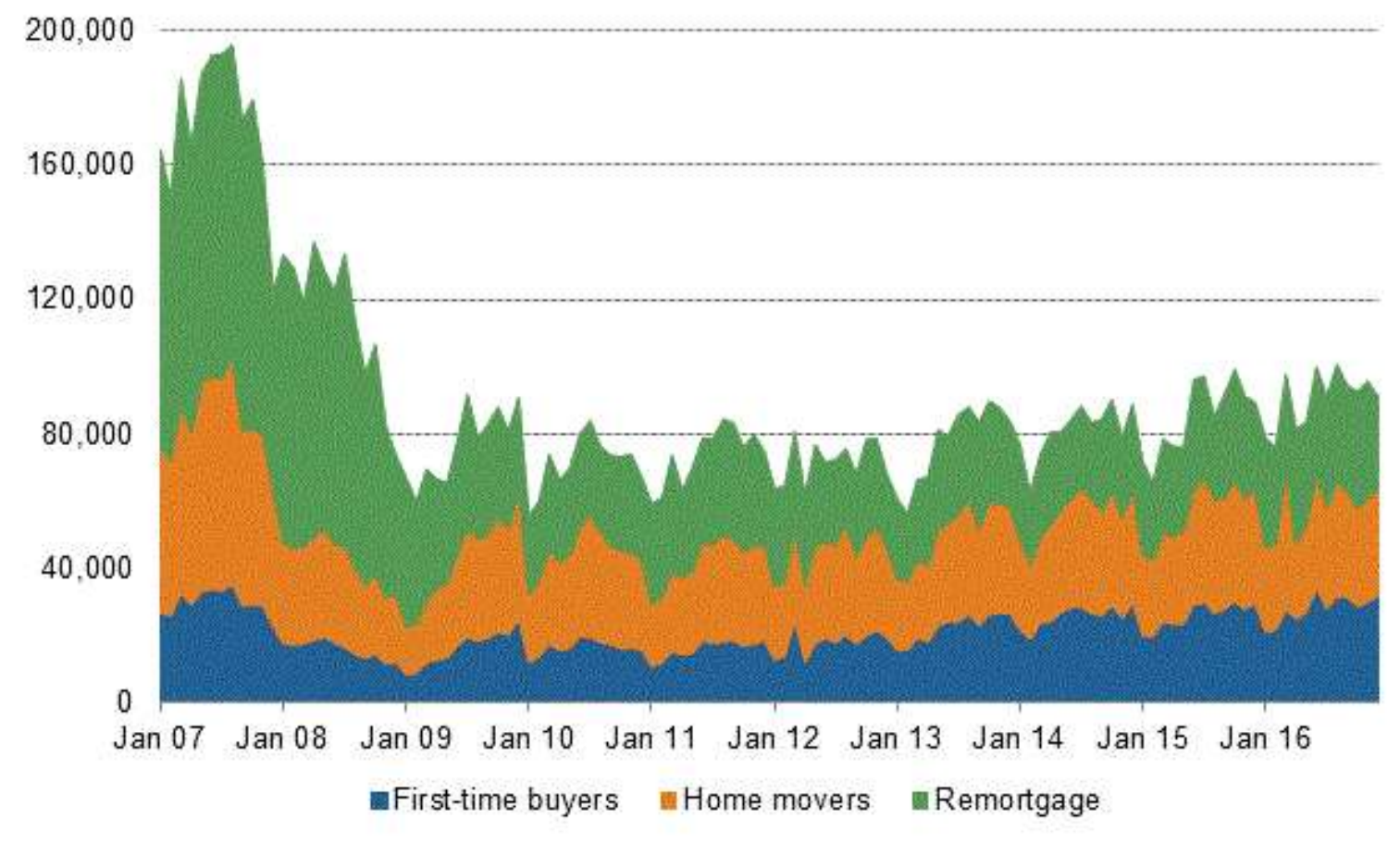

1. Totals shown are estimates grossed up from the sample of lenders reporting to reflect total market size.

2. First time buyer numbers will include some buyers who have previously owned a property before, but are not in owneroccupation at the time of this purchase. Estimates from the Survey of Housing suggest that around $20 \%$ of stated firsttime buyers may in fact fall into this category.

Fig 4: Number of loans to home-owners, 2007-2016 in the UK (CML, CML Regulated Mortgage Survey, 2017).

Considering increasing cost of loans for the Help to Buy scheme, CLT SEHM adoption has been relegated to mainly rural communities with huge variations in property prices (Paterson and Dyson, 2011). Hence, its prospect as a viable option is limited, particularly in the urban regions. This among other identified barriers appeared to have hampered its popularity among lenders (Redacted Reference: Authors). Prompted with the aforementioned FTB homeownership structural dilemma as reviewed and a housing delivery model underrepresented in a competitive housing development sector; this study sought to address financial interoperability issues that might be hampering the CLT SEHM and FTB homeownership synergy.

\section{Research Methodology}

This chapter describes the various stages for the interoperability development process. Potential issues associated with the CLT SEHM adoption in relieving ownership problems among FTBs where identified through triangulated data sources from literature, interviews and surveys, see (Table 2) showing enquiry description for both semi-structured interviews and the questionnaire survey.

\begin{tabular}{lll} 
Category & Description/Rationale & $\begin{array}{l}\text { Semi- } \\
\text { structured } \\
\text { interview }\end{array}$ \\
\hline
\end{tabular}




\begin{tabular}{|c|c|c|c|c|}
\hline & & $\begin{array}{l}\text { No of } \\
\text { responses }\end{array}$ & $\begin{array}{l}\text { No of } \\
\text { questionnaire } \\
\text { responses }\end{array}$ & $\begin{array}{l}\text { Key } \\
\text { references } \\
\text { (Nvivo 9.0) }\end{array}$ \\
\hline Industry & $\begin{array}{l}\text { Mortgage and housing finance } \\
\text { representatives. }\end{array}$ & 6 & \multirow[t]{3}{*}{$\mathrm{n} / \mathrm{a}$} & \multirow[t]{3}{*}{26} \\
\hline $\begin{array}{l}\text { Community } \\
\text { development }\end{array}$ & $\begin{array}{l}\text { CLT SEHM key enablers from } \\
\text { implementation stages to completion. }\end{array}$ & 4 & & \\
\hline $\begin{array}{l}\text { Academic } \\
\text { Researchers }\end{array}$ & $\begin{array}{l}\text { Housing and construction academics } \\
\text { with active research in sustainable } \\
\text { communities and involvement. }\end{array}$ & 8 & & \\
\hline $\begin{array}{l}\text { Interest } \\
\text { groups. }\end{array}$ & $\begin{array}{l}\text { Community networks: to capture nuance } \\
\text { and perceptions of representative sample } \\
\text { of broad base UK homeowners and FTBs } \\
\text { interested in community building } \\
\text { initiatives. }\end{array}$ & $\mathrm{n} / \mathrm{a}$ & 91 & $\mathrm{n} / \mathrm{a}$ \\
\hline
\end{tabular}

Table 2: Enquiry Description

\subsection{The Interoperability Development Process}

The interoperability development process (as a strategic tool to help facilitate synergy between emerging housing delivery models and homeownership among FTBs) was carried out in the following phases. See also, (Appendix C).

\section{Phase 1: Establishment of the need of CLT SEHM in FTB homeownership.}

In order to define the scope and problem statement for the development of successive alternative solutions such as the CLT SEHM, relevant literature was vigorously reviewed. Findings revealed the failings of traditional LCHO models and need for alternatives to tackle FTB homeownership dilemma. Also, the state of low representation and employment of the CLT SEHM in home delivery in the UK was also confirmed despite its demonstrable benefits.

\section{Phase 2: Identify barrier sources hampering FTB and CLT SEHM financial interoperability.}

As a precursor to the third phase, the study reflected on the cogent need to shed more light on the benchmarks and financial issues that best represents those that are interested in this option. To achieve this, the research investigated barrier sources to this synergy, hence derived assessment indicators and measures. A number of tape recorded anonymous semi-structured interviews as informed by the first phase were targeted at key informants of the National Community Land Trust Network (NCLTN), academics inclined towards housing and banking institution representatives offering loan facilities to FTBs.

The Semi-structure interviews conducted were based on the following list of question areas:

- From a community housing perspective, how can you classify FTBs?

- What are the possibilities for CLT SEHM engagement in FTB property ownership?

- How can you improve the state of financial synergy between FTBs and the CLT SEHM?

Phase 3: Derive assessment indicators/measures through content Analysis and concept map for CLT SEHM Interoperability issues associated with FTB homeownership 
In order to fulfil the third phase objectives, data generated from phase 2 of the process were transcribed. Then a text analysis was carried out employing (Nvivo 9.0). The coding and evaluation process resulted in a concept map with 2 major thematic clusters/Nodes and their respective ramifications/sub nodes on associated issues with FTB and CLT SEHM associated issues (Appendix D).

\section{Phase 4: Establish critical benchmark factors for FTB and CLT SEHM financial interoperability}

From the phase 3 of the study, generated indicators from the text analysis and concept map where empirically validated to establish rationale for financial interoperability optimisation factors regarding FTB and CLT SEHM synergy in comparison to traditional options. This included a binary logistic regression model to verify propensity to save among potential target sample, and also clarify if there are associations with other research variables. The binary logistic regression model results on income classification were further used to analyse implications for Housing Model Resale/Transfer between assessed housing delivery models. Based on the interoperability analytical process validated constructs were refined to reflect the evidence of face and content validity. This was carried out by the administration of the draft process to four experts including top built environment academics and housing practitioners. The selection process was based on the criteria of experience in built environment and familiarity with the study's context in housing delivery. The consolidation of these phases resulted in the Interoperability Development and Optimisation Process.

\subsection{Summary of Interview Analysis}

An inter-organisational category approach was adopted for the interview in order to obtain a fair, well rounded data that allowed for the all-encompassing analysis of differing opinions. This study's enquiry process utilised key informants for its semi structured interviews, due to low level of mutual housing knowledge among both housing experts and laymen alike (CCMH, 2009). The key informant approach is based on a technique that utilises rich research specific information sources. Respondents from these organisations include those involved in property mortgage application assessments for (banking institutions), in depth involvement in CLT SEHM development from implementation stages to completion for community organisations, and housing academics with active research in sustainable communities and involvement. Since the total population of possible key informants are small, 8 representatives for each organisation category were initially deemed suitable. However, as new themes stopped emerging, thematic and theoretical saturation was reached at varying levels for each category, hence the disparity in the number of interview respondents, i.e. Industry (6), Community development (4) and Academic Researchers in study area (8).

Notably, for the community development category, thematic and theoretical saturation was reached at just four respondents, this was attributed to the respondents' selection criteria which included a robust practical experience database that has been garnered from active field presence, involving the day to day meeting and dealing with local CLT advocates and enthusiasts, coupled with an in depth involvement in CLT development from implementation stages to completion with an operational scope that cuts across well over 10 local authorities or even more. Furthermore, a narrow enquiry framework targeted at respondents with a rather similar but robust experience pattern that focused on interpretation of stakeholder policies and its actual impact on FTBs and CLT practitioners significantly accelerated thematic saturation. Similarly, for the industry category, perceptions were found to be more regimented based on 
industry standards, therefore thematic saturation was reached much earlier than other category of respondents. For the academic category, selection criteria included active research in sustainable housing, communities and involvement. Unlike, the more confined perceptions sometimes defined by industry standards as obtained from both industry and community development interviewees, the 'academic researcher' respondents provided much more varying perceptions due to a more nuanced housing research experience in the study area and what appears to be less boundaries in communicating their ideas. Although their perceptions helped minimise bias, in this case it appears to have inversely affected thematic and theoretical saturation rate as new themes stopped emerging significantly later compared to other categories at eight interviews.

\section{Conflicting benchmarks among stakeholders on FTB}

In regards to housing initiatives concerning CLT SEHM, the FTB homeownership discourse has revolved around the context of the role of government LCHO schemes as identified in literature, however little or no research has been carried in regards to CLT SEHM utilisation in regards to FTB homeownership. Therefore, defining the demographic characteristic of this peculiar population group was deemed essential because interview findings revealed that there are conflicting outlooks on what defines FTBs.

'[...] persistent ambiguity on how to define the demographical characteristics of who FTBs are, particularly when it comes to implementing policies to tackle inherent barriers'

Notably from a community development perspective; responses agree with literature on the demographical classification of 18-24yr olds as those most affected by reduction rates in homeownership (Wallace et al, 2009), a stark deviation from an average FTB age of 29 yrs.' as cumulated by CML (2013). Findings however pointed out consistency and subjectivity issues for the 18-24yrs categorisation.

[...] 18-24yrs classification could represent a microcosm for conducting studies on the wider yet undefined FTB sample, but might not be accurate for more practical purposes such as policy implementation.

\section{Personal and finance inadequacies}

This cluster highlighted poor FTB performance in mortgage eligibility as identified by literature. Responses provided an insight that mostly attempts to attribute this issue to solely funding problems associated with FTB population shortcomings. Also salient is the notion that policies and qualification procedures of lenders are part of the greater problem in regards to eligibility for the CLT SEHM delivery structure.

'The failure of FTB schemes to accommodate the core section of the most in need FTBs [1824yrs] [...causes] a 'ricochet effect' on non-benefiting FTBs who are compelled to jostle with inflated housing prices on the open market'.

Apparently, findings from the responses also reflected difficulties concerning personal funding sources for individual FTBs.

'Alleviation of FTB housing problems is hinged on the availability of funding to would be lenders'. If the feasibility and pathway towards funding are unclear due to housing model structure; 'The difficulty of FTBs obtaining mortgages could remain persistent'. 
Alongside the most common FTB housing finance problem identified included credit problems, mortgage finance, level of income, down payment problems. Interview findings further suggested that the most peculiar problem seemingly overlooked is the CLT SEHM land equity structure which greatly differs to conventional ownership arrangements. Therefore, this might be deemed as a potential source of obstacle regarding CLT SEHM successes and interoperability with FTBs in comparison to typical government backed policy arrangements like the LCHO schemes.

\section{Empirical Analysis and Findings}

The interview process informed the validation of themes through a questionnaire survey (purposive sampling), of which findings were subsequently analysed with the SPSS software to ascertain rational and implications. This section addressed analysis that was carried out on generated indicators to establish rationale for interoperability factors aimed at improving FTB and CLT SEHM synergy in comparison to traditional alternatives. Please see (Table 3 ) for the analytical process.

\begin{tabular}{|c|c|c|}
\hline $\begin{array}{l}\text { Major Clusters } \\
\text { Phase } 1\end{array}$ & $\begin{array}{c}\text { Interoperability indicators } \\
\text { Phase } 2 \text { and } 3\end{array}$ & $\begin{array}{c}\text { Interoperability rationale } \\
\text { Phase } 4\end{array}$ \\
\hline \multirow[t]{2}{*}{$\begin{array}{l}\text { Conflicting benchmarks } \\
\text { among stakeholders on } \\
\text { FTB }\end{array}$} & \multirow[t]{2}{*}{$\begin{array}{l}\text { Age, homeownership status and } \\
\text { income benchmark issues }\end{array}$} & $\begin{array}{l}\text { Age and homeownership status } \\
\text { - Homeownership and age association: } \\
\text { Interoperability implications. }\end{array}$ \\
\hline & & $\begin{array}{l}\text { Housing ownership category and Income } \\
\text { - Homeownership and income } \\
\text { association and implications. }\end{array}$ \\
\hline \multirow[b]{2}{*}{$\begin{array}{l}\text { Personal and finance } \\
\text { inadequacies }\end{array}$} & \multirow{2}{*}{$\begin{array}{l}\text { CLT SEHM structural } \\
\text { implication on personal housing } \\
\text { finance issues }\end{array}$} & $\begin{array}{l}\text { CLT SEHM structure as a housing finance } \\
\text { problem. } \\
\text { - Interoperability significance of land } \\
\text { equity issues alongside identified } \\
\text { finance problems. }\end{array}$ \\
\hline & & $\begin{array}{l}\text { Propensity to Save (Influences) } \\
\text { - } \quad \text { Propensity to save among population } \\
\text { groups. } \\
\text { - } \\
\text { Propensity to save and implications on } \\
\text { homeownership category and adjunct } \\
\text { variables. } \\
\text { - FTB interoperability rational: Income } \\
\text { multiple and resale value appraisals }\end{array}$ \\
\hline
\end{tabular}

Table 3: Interoperability Optimisation: Analytical Process

To achieve these objectives, questionnaire surveys (149) were electronically distributed (purposive sampling) through a NCLTN database and other community interest groups involved in enabling community based initiatives and development. This approach provided a pool which helped capture the nuance and perceptions of a representative sample of broad base UK homeowners and FTBs interested in community building initiatives. There was a $61.07 \%$ return rate and 91 responses (Table 2). A random representation of the target databases was sought irrespective of location. The questionnaire build up comprised of simple and mixed format multiple choices and five point likert scale questions (mostly closed). The survey constructs where further analysed with the SPSS software preceding a measure of internal 
consistency. A Cronbach's Alpha coefficient of $(\alpha=0.737)$ was obtained from the reliability test, which is within an acceptable range.

\subsection{Profile: Age, homeownership and Income Category}

This analysis is aimed at defining homeownership status according to age group and the category most likely to represent FTBs. The survey takers were asked how they viewed their housing ownership status and their age categories in-line with findings for the Phases 1,2 and 3 processes. Cross tabulation results were generated by analysing homeownership status among the various respondents. The phase 1 of the interoperability process suggested that $18-24 \mathrm{yrs}$ category represents the groups most affected by the failures of both previous and new LCHO Models. Survey result verified that FTBs are not restricted to any age category; in fact there is a representation of FTBs across all studied age groups 18-24yrs (94.4\%), 25-35yrs (82\%), 36$45 y r s(48 \%), 46-55 y r s(61.5 \%)$ and above 55yrs (10\%) respectively. Survey results of the studied population further accentuated more precisely that homeownership is more represented among older age categories. Moreover, $0.0 \%$ respondents identified themselves as homeowners within the 18-24yrs age group. Conversely, $90 \%$ of respondents above $55 \mathrm{yrs}$ identified themselves as homeowners.

Result of chi-square test carried out to verify the premise of this finding indicated that homeownership category is significantly associated with age group: $\mathrm{x}^{2}(8, N=90)=30.574, p$ $<.001$. This analysis is aimed at establishing an interoperability benchmark for homeownership status and associated links to income groups among targeted population sample. Results of chisquare test carried out indicated that homeownership category is significantly associated with income status: $\mathrm{x}^{2}(10, N=90)=41.615, p<.001$. Results revealed that the most relevant income group among FTBs is the $(£ 10,000-£ 25,999)$. However, among homeowners the most relevant income group is the (More than £25999) income category. The results suggest that the higher the corresponding income category the higher the representation of homeowners.

\subsection{CLT SEHM structure as a housing finance problem}

Information sought here included, whether the concept of forfeiting freehold on homeownership in lieu for a reduced housing cost is as much of a concern for home buyers compared to other encumbrances such as credit availability, mortgage financing, down payment and income. Associations among (phases 1, 2 and 3) findings on housing finance problems and targeted population group responses where tested alongside. In order to evaluate the significance of land equity/CLT SEHM structural issues as a barrier to model adoption in comparison to other identified housing finance problems, the respondents were asked to indicate the relevance of each of the aforementioned variables on a five point likert ranking scale, where $1=$ Lowest Relevance to $5=$ Highest Relevance. 


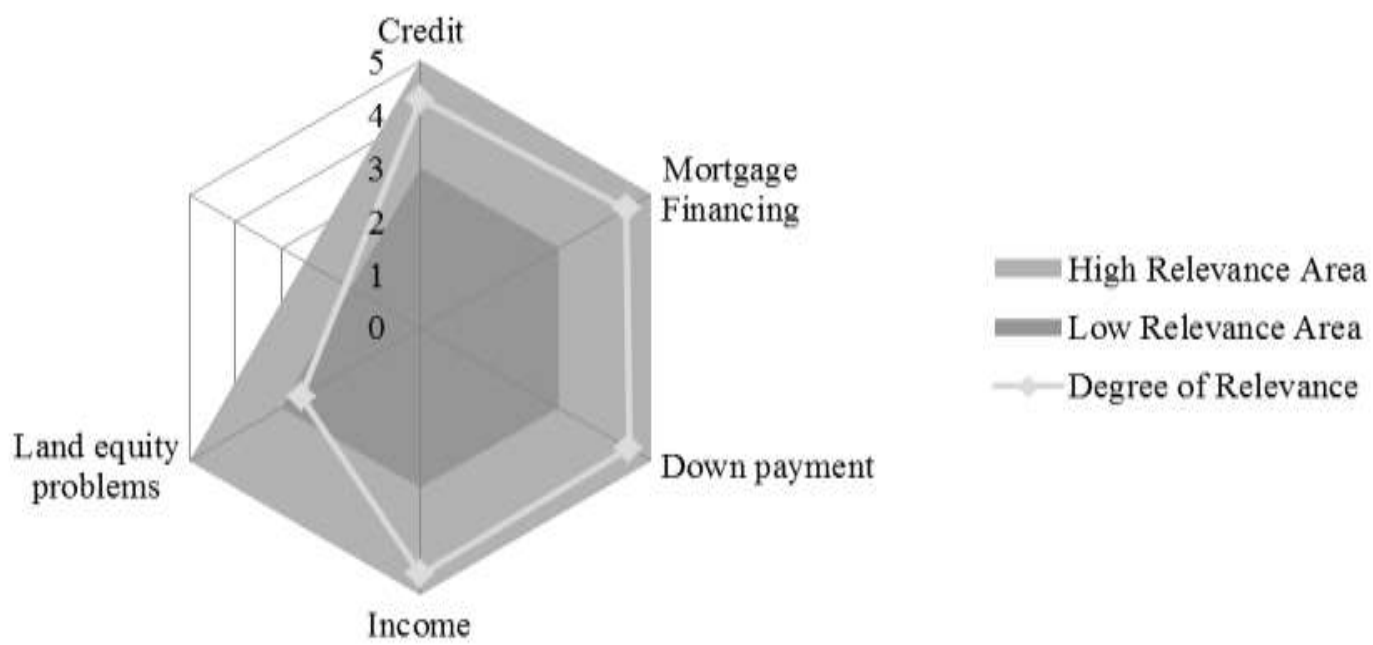

Fig 5: Degree of relevance of housing finance issues

A radial chart was generated to ascertain a mean distribution for the relevance of each variable (Fig 5). Although results indicated significant associations for all the variables; 'Relevance of credit problems': X2 (3, N = 91) = 94.27, $\mathrm{p}<.01$; 'Relevance of mortgage finance': X2 (3, N $=91)=77.92, \mathrm{p}<.01$; 'Relevance of down payment problems': $\mathrm{X} 2(3, \mathrm{~N}=91)=81.09, \mathrm{p}<.01$; 'Relevance of level of income': $\mathrm{X} 2(2, \mathrm{~N}=91)=57.38, \mathrm{p}<.01$; 'Relevance of land equity problems': X2 $(4, \mathrm{~N}=91)=30.70, \mathrm{p}<.01$, findings showed low levels of relevance for land equity problems as a housing finance issue compared to other tested variables.

\subsection{Propensity to save: Logistic Regression Model}

Findings from the phases 2 and 3 of the interoperability process suggested low levels of savings among FTBs seeking conventional housing options. However, it is crucial to this study to not only verify propensity to save among potential target sample, but to also clarify if there are associations between propensity to save and other research variables. Respondents were asked whether they are planning/currently saving towards homeownership, this helped clarify if propensity to save is influenced by respondents' housing situation or perhaps other factors. For a niche target sample, there is little to indicate which variables are expected to be reliable predictors (Field, 2009). Therefore, a 2 step binary logistic regression was performed to ascertain the effects of homeownership category, income and other study variables on the likelihood that participants are planning/currently saving towards homeownership.

For more than one independent variables and one categorical dependent variable, the binary logistic regression (multivariate) was considered most appropriate. With the following; $P$ : probability of Y occurring; $e$ : natural logarithm base; $\beta_{o}$ interception at y-axis; $\beta_{1:}$ line gradient; $\beta_{n}$ : regression coefficient of $x_{n} ; x_{1}$ : predictor variable; $x_{n}$ : predicts the probability of $\mathrm{Y}$. The analysis was based on the following regression formula:

$$
P(Y)=\frac{e^{\left(\alpha+\beta_{o}+\beta_{1} x_{1}+\beta_{2} x_{2}+\cdots+\beta_{n} x_{n}\right)}}{1+e^{\left(\alpha+\beta_{o}+\beta_{1} x_{1}+\beta_{2} x_{2}+\cdots+\beta_{n} x_{n}\right)}}
$$

Where: $\alpha$ is a constant and $\beta i$ are the regression coefficients for each variable representing homeownership category and income, $\mathrm{X}_{\mathrm{i}}$ for $\mathrm{i}=1,2, \ldots \mathrm{n}$. Assuming that; $P(Y)=1$ or 0 ; 
therefore, $Y=1$ if the respondent is planning/currently saving towards homeownership and $Y=0$, if the respondent is not saving (Table 4).

\begin{tabular}{llll} 
Data Variable & Data Explanation & Data Type & Codes \\
\hline Dependent Variable & & & \\
Propensity to save & No; Yes & Binary & $0=$ No; $1=$ Yes \\
\hline Independent Variables & Homeownership & & $\begin{array}{l}0=\text { Homeowners/Other } \\
1=\text { FTB }\end{array}$ \\
HC10 - Homeownership & Classification & Binary & \\
\hline I7 - Income & Income Classification & Binary & $\begin{array}{l}0=(\text { More than } \\
£ 26000) \\
\end{array}$ \\
& & & $\begin{array}{l}1=(£ 10,000- \\
£ 25,999) .\end{array}$ \\
\hline
\end{tabular}

Table 4: Coding of variable influences on propensity to save

This study recorded: $R^{2}=0.14$ (Cox \& Snell), 0.197 (Nagelkerke). The maximum value that the Cox \& Snell $\mathrm{R}^{2}$ attains is less than 1 . However, the Nagelkerke $\mathrm{R}^{2}$ is an adjusted version of the Cox \& Snell $\mathrm{R}^{2}$ and covers the full range from 0 to 1 . It is therefore considered more reliable. The $\mathrm{R}^{2}$ statistics can be referred to as effect size which validates the suitability of the study's construct in predicting the response variable (Bewick, Cheek, \& Ball, 2005). Therefore, the value of 0.197 indicates that the model is useful in predicting propensity to save among target communities. From the odds prediction equation: $\left[o d d s=e^{\alpha+\beta \times}\right.$ ], if a respondent is a FTB, $[\mathrm{HC} 10=1]$, the odds for propensity to save towards housing is: $\left[\right.$ odds $\left.=e^{.274+2.025(1)}=9.964\right]$; also if a respondent is a homeowner or other, $[\mathrm{HC} 10=0]$, the odds of saving towards housing is: [odds $\left.=e^{.274+2.025(0)}=1.315\right]$. In order to generate the odd ratio predictions for the model, i.e. $\operatorname{Exp}(B)$ was computed as follows: $\left[\mathrm{e}^{\wedge}\left(\mathrm{b}_{0}+\beta_{1}\right) / \mathrm{e}^{\wedge} \beta_{0}=7.579\right]$. See (Table 5), for the remaining results.

Variables in the Equation

\begin{tabular}{|c|c|c|c|c|c|c|c|c|c|}
\hline & & \multirow[t]{2}{*}{ B } & \multirow[t]{2}{*}{ S.E. } & \multirow[t]{2}{*}{ Wald } & \multirow[t]{2}{*}{$\mathrm{df}$} & \multirow[t]{2}{*}{ Sig. } & \multirow[t]{2}{*}{$\operatorname{Exp}(B)$} & \multicolumn{2}{|c|}{ 95\% C.I.for EXP(B) } \\
\hline & & & & & & & & Lower & Upper \\
\hline \multirow{2}{*}{ Step 1} & $\mathrm{HC} 10(\mathrm{FTB})$ & 1.035 & .499 & 4.303 & 1 & .038 & 2.814 & 1.059 & 7.480 \\
\hline & Constant & -.587 & .675 & .755 & 1 & .385 & .556 & & \\
\hline \multirow{3}{*}{ Step 2} & I7(£10,000-£25,999) & -.543 & .203 & 7.164 & 1 & .007 & 0.581 & .391 & .865 \\
\hline & $\mathrm{HC} 10(\mathrm{FTB})$ & 2.025 & .676 & 8.971 & 1 & .003 & 7.579 & 2.014 & 28.528 \\
\hline & Constant & .274 & .798 & .118 & 1 & .732 & 1.315 & & \\
\hline
\end{tabular}

Table 5: Summary of Binary logistic regression predictions for propensity to save towards housing

In summary, age and perception of land equity as a problem did not improve the predictive power of the regression model (rather there was increase in the amount of unexplained variance), hence were excluded from the final model. In summary, a respondent who is considered a FTB has a 2.814 times more chance of saving towards homeownership, and a 7.579 more chance of a higher propensity to save if income category is considered (Step 2). In the same context, a respondent who falls within an income range of $£ 10,000-£ 25,999$ per 
annum, (which is the most relevant income group in regards to FTBs) has 0.6 times more chance of saving towards homeownership (Table 6).

\section{Implications for Housing Model Resale/Transfer Evaluation}

Further analysis was carried out to compare the LCHO models to the CLT SEHM regarding income classification results from the regression model. This was done to test model interoperability within the targeted survey sample.

Average house price 2002: $£ 112,375$; Average house price 2017: $£ 226,000$

The HelptoBuy scheme provides an equity loan of $20 \%$ of target property

Assuming initial owner purchased the property with a $75 \%$ mortgage for

According to (Nationwide 2011) as at year 2002;

FTB gross house price to earnings ratio was 3.3 (mortgage multiple of $3.3 \mathrm{x}$ income)

Hence, annual income at 2002 if average house price is $£ 163,177$

$£ 25,539$

15 years later assuming house is resold at average price

$£ 226,000$

Average house price increase 2002-2017

$£ 113,625$

While average wage increase from 2002-2017

$£ 1,661$

Therefore; $20 \%$ capital receipt from resale for recycled subsidy

$£ 45,200$

Recycled subsidy now assists towards purchase price@75\% mortgage

FTB household purchasing property at an average income (2017)

Will result in a mortgage multiple of:

$6.2 \mathrm{x}$

House price to earnings ratio:

In comparing both house prices to earnings ratio over the 15 year period (3.3 to 6.2):

This shows that the scheme has become a lot less attractive to new beneficiaries.

\section{CLT SEHM Illustration}

The CLT equity sharing formula in comparison to the above illustration using same assumptions and time frame

After Open Market Value at initial purchase at year 2002

Assuming initial purchaser obtains subsidy@ 20\% of target property

Initial purchaser acquires the target property@ $75 \%$ mortgage

$15 \mathrm{yrs}$ after property is resold at average price in 2014

House price increase 2002-2017

In place of the recycled subsidy in the first illustration, the CLT SHEM uses the resale formula which involves:

The repayment of the initial purchaser's mortgage

House price increase@20\%

Initial purchaser's return after resale

$£ 112,406$

New open market value at resale 2017

$£ 226,000$

New Resale Price for next beneficiary

Initial Purchaser's return = Initial Purchaser's Mortgage + House price Increase@ 20\%. New Resale price for next beneficiary = New OMV- Initial Purchaser's return.

At $£ 113,594$ of resale price, house price to earning ration at $2017 @ £ 27,200$ income 4.2 In comparison to the Help to Buy illustration of 6.2

Table 6: Housing Model Resale/Transfer Evaluation (Study’s Analysis, 2017) 
This analysis involved the income multiple and resale value appraisal, aimed at linking the UK average property price to income by adjusting resale price in proportion to the UK median income from 2002 till date (2017). The illustration (Table 6) was based on the CLT SEHM and HTB scheme which mandates beneficiary contribution of at least $5 \%$ of the property price as deposit. This is then backed by government loans with an upper limit of $20 \%$, while a mortgage of up to $75 \%$ covers the remaining of the property cost (CML, 2017). The study adopted the most recent Office of National Statistics (ONS) House Price Index - of which average house prices in the UK have increased by 5.4\% as at September 2017 (up from $4.8 \%$ in August 2017), and an average property price of $£ 226,000$ in UK (Office of National Statistics, 2017). Also, adopted was the ONS (2017) figure of $£ 27,200$ average Annual Survey of Hours and Earnings. Assumptions: (5\% deposit liability is not transferable for both models).

Study's findings indicated that the house price to earnings ratio at resale/transfer is 4.2 for the CLT SEHM and 6.2 for the Help to Buy scheme; this makes the CLT SEHM more favourable for FTBs (Table 7). Implications for this study at the upper income classification limit $(£ 25,999)$ for FTBs is that, considering a CLT SEHM resale value of $£ 113,594$, the house price to earnings ratio at resale/transfer was 4.4. Therefore, compared to the less sustainable LCHOS's (HTB) at 6.5 and a resale/transfer value of $£ 169,500$ over a $15 \mathrm{yr}$ period, this builds a strong interoperability rational for the CLT SEHM.

\section{Discussion and Conclusion}

\section{Financial interoperability optimisation process}

From the study's established findings, the Interoperability Optimisation Process (Fig 6) was developed. Implications are discussed in the subsequent paragraphs.

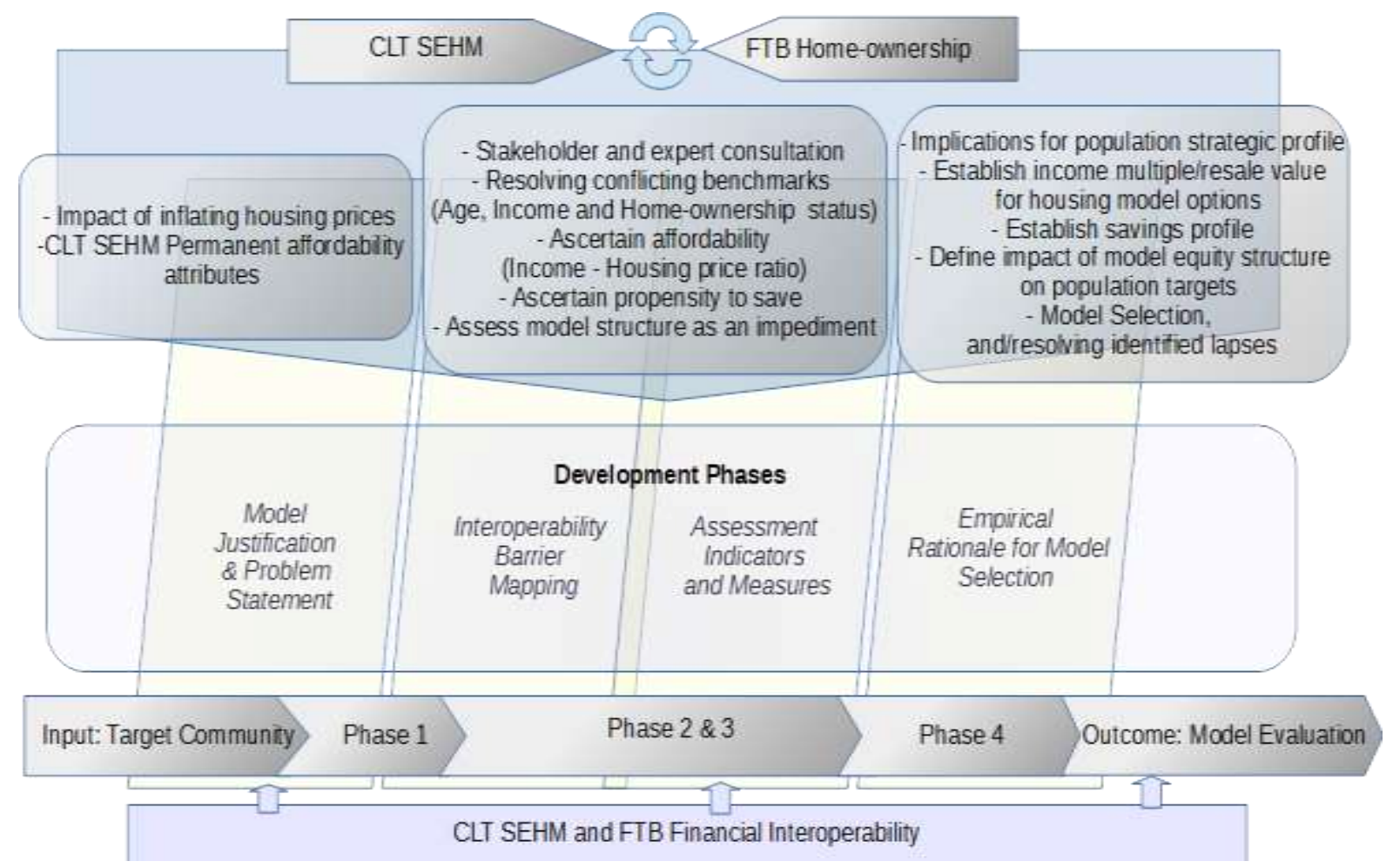

Fig 6: Study’s Interoperability Optimisation Process 
Interview findings from the phase $2 \& 3$ (defining interoperability indicators) identified the 18$24 \mathrm{yrs}$ as the most representative sample for FTBs. However there was greater representation of FTBs among the 25-35yrs age category. On this premise, the 25-35yrs age group signifies a representative policy benchmark local councils, government or private developers considering the CLT SEHM in lieu of (or alongside) the LCHO models for housing delivery. Focusing on this age group facilitates a more efficient CLT SEHM interoperability strategy in mainstream housing delivery policies. However, this finding does not indicate the need for a complete shift of focus from the 18-24yrs category; rather it further reiterates its importance as a crucial interoperability benchmark for research and knowledge sharing build-up on the ideals of community housing initiatives based on the CLT SEHM as a homeownership vehicle for even the most at risk age groups.

Further assessments showed that the $(£ 10,000-£ 25,999)$ category, where FTB representation was highest, falls just short of a feasible range for an interoperable income. However, for the upper limit of $(£ 25,999)$, this category indicated a 4.4 house price to earnings ratio at transfer/resale for the CLT SEHM. From (Table 6), this is much closer to sustainable targets of 4.2, which outperform both the 5.3 ratio - considered unsustainable by Office of National Statistics (2014) - and the LCHOS figure of 6.5, considering a UK average income of £27,200. This lends credence to the IMF reservations concerning the LCHO Help to Buy scheme's effect on inflation of housing prices, which reduces long and short term affordability for FTBs. To this effect, despite the increasingly unsustainable interoperability levels for FTBs earning less than the $£ 25,999$ upper limit (about a fifth of all borrowers) (National Audit Office, 2014), the CLT SEHM has a more attractive house price to earnings ratio compared to the LCHOS regardless of the income group.

Therefore, in order to optimise this advantage, options for increased government subsidies and planning concessions for CLT SEHM housing projects are recommended. Furthermore, policies favouring a shift towards relaxation of planning laws and reduction of Local Authority (LA) charges on small and medium scale developers that might want to employ the CLT SEHM for housing delivery should incentivise and drive innovation in the cost reduction of homeownership. On the long run, this could extend the frontiers of research in the facilitation of more bespoke affordable housing and rent purchase hybrid schemes to cater for the most at risk FTB groups, thus ease savings for mortgage deposits. Moreover, contrary to the notion that low propensity to save among FTBs is an interoperability barrier to engaging the CLT SEHM for housing ownership, the regression model predicted that FTBs within the study's target population group are far more likely to save towards homeownership.

In regards to housing model structural limitations, the interoperability process indicated that land equity issues in regards to the CLT SEHM is not viewed as much of a concern compared to other 'finance problem' related variables among surveyed population groups. This partly nullifies the CLT SEHM structure as being a barrier to interoperability among FTBs. Moreover, both age and perception of land equity as a problem did not influence propensity to save among the respondents according to the final regression model. On this note, this study recognises the culpability of the possible influence of low levels of subject development model sensitisation on perceptions among target populations or communities, hence the poor performance of the CLT SEHM in mainstream housing delivery. Therefore, the importance of improving the efficiency of knowledge sharing conduits between community development networks, housing institutions, project beneficiaries and other relevant stakeholders is considered crucial to efficient interoperability. 
In summary, this study assessed financial interoperability implications associated with FTBs in housing development and the role of the CLT SEHM. Outcomes included the development of an interoperability optimisation process to help enhance synergy between the CLT SEHM and FTBs in housing delivery. Findings identified positive implications for the population profile and also more sustainable results for income multiple and property transfer/resale value for the CLT SEHM compared to conventional models. This research therefore provides a good starting point for improving efficiency in the introduction of emerging/renewed alternative models into operational capacities in order to help stimulate their adoption in housing delivery and local development. For future research, this study suggests the further exploration of interoperability issues among knowledge sharing conduits existing within community development networks, housing institutions, housing seekers/beneficiaries, and other development stakeholders. Moreover, the applicability of interoperability processes in other built environment areas, incorporating broader communities/specific projects can be further researched.

\section{References}

Andrew, M. (2005). The Changing Route To Owner Occupation: The Impact Of Household Formation and Borrowing Constraints On Young Adult Homeownership In Britain. London: Economic and Social Research Council.

Asthana, A., \& Dyer, E. (2011, January 2). 'Horrendous' housing trends slam door on firsttime buyers. The Observer, p. 8.

(Redacted Reference: Authors)

Birchall, J. (2004). Cooperatives and the Millennium Development Goals. Geneva: International Labour Office.

Boleat, M. (1997). 'The politics of home ownership', in Williams, P. (Ed.), Directions in Housing Policy: Towards Sustainable Housing Policies for the UK. London: Paul Chapman Publishing Limited.

CCMH (2009) Bringing democracy home, West Bromwich: CCMH

CEN. (2009). European Committee of Standardisation: Report on Requirements. Brussels: CEN.

CFS. (2009). Engaging financial institutions in developing Community Land Trust mortgage Products. Salford: Community Finance Solutions.

Clark, M. (2012). Housing Cooperatives: Are we better together? Retrieved March 13, 2014, from http://www.guardian.co.uk/housing-network/2012/jan/13/housing-cooperativesaffordable-alternatives

CML. (2008, October 14). Lending declines further in August. CML . 
CML. (2011). First-time buyers and affordability: a fresh perspective. London: Council of Mortgage Lenders.

CML. (2013). 42\% more first-time buyers in May than a year ago. Retrieved February 9 , 2014, from http://www.cml.org.uk/cml/media/press/3586

Community Finance Solutions. (2009). Evaluation of the National Community Land Trust Demonstration Programme 2006-2008. Salford: Community Finance Solutions.

Comunities and Local Government. (2008). Community Land Trusts: A Consultation. London: Comunities and Local Government.

Coughlan, J., Robert, D., Macredie, \& Patel, N. (2011). Understanding the consumption process through in-branch and e-mortgage service channels: A first-time buyer perspective. International Journal of Bank Marketing, 29(2), 148-167.

Davis, J., \& Demetrowitz, A. (2003). Permanently Affordable Homeownership: Does the Community Land Trust Deliver on Its Promises? Burlington: BCLT.

Dolphin, T. (2013). The bittersweet recovery. London: IPPR.

European Committee for Standardisation. (2014). Report on Requirements . Brussels: CEN. Institute of Directors. (2013). The world must have gone mad - housing market needs help to supply, not help to buy. London: IOD.

Land Registry. (2014). Land Registry House price Index. London: Crown.

Livette, M. (2006). The importance of tenure to retirement housing purchasers and the impact of culture upon their attitudes to tenure. Property Management, 24(5), 464-478.

Macrory, I., \& ONS. (2012). Measuring National Well-being-Households and Families. London: Crown.

Mayor of London. (2004). Community Land Trusts \& Mutual Housing Models: A research report for the Mayor of London. London: Greater London Authority.

Monk, S., \& Whitehead, C. (2010). Housing More Affordable: The Role of Intermediate Tenures. Chichester: Wiley.

Monk, S., Whitehead, C., \& Burgess, G. (2010). How can the planning system deliver more housing? York: Joseph Rowntree Foundation.

National Audit Office. (2014). The Help to Buy equity loan scheme. London: Department for Communities and Local Government.

NCIOC. (2008). NCOIC Interoperability Framework and NCOIC Patterns Overview. Washington: Network Centric Operations Industry Consortium. 
Office of Budget Responsibility. (2013). Office for Budget Responsibility: Economic and Fiscal Outlook - Cm. 8748. London: The Stationery Office.

Office of National Statistics. (2013). Annual Survey of Hours and Earnings. London: Crown.

Office of National Statistics. (2014). House Price Index, April 2014. London: Crown.

Paterson, B., \& Dayson, K. (2011). Proof of Concept. Salford: University of Salford/CFS.

Poon, J., \& Garratt, D. (2012). Evaluating UK housing policies to tackle housing affordability. International Journal of Housing Markets and Analysis, 5(3), 253-271.

Richards, R. (1984). The Right to Buy provision reconsidered. Property Management, 2(1), 27-32.

RICS. (2014). RICS Policy Position: Help to Buy. Retrieved April 19, 2014, from http://www.rics.org/uk/about-rics/what-we-do/influencing-policy/policypositions/policy-position-uk---help-to-buy/

Sartipi, K., \& Dehmoobad, A. (2008). Cross-Domain Information and Service Interoperability. (pp. 25-32). Linz: ACM.

Smith, J., Pannell, B., Holmans, A., \& Thomas, A. (2005). Understanding First-time Buyers. London: Council for Mortgage Lenders.

The Building Societies Association . (2014). BSA reports lending to first time buyers up by 50\%. Retrieved Feb 12, 2014, from http://www.bsa.org.uk/press-office/pressreleases/bsa-reports-lending-to-first-time-buyers-up-by-\%281\%29

Wallace, A., \& Jones, A. (2009). Rapid Evidence Assessment of the economic and social consequences of worsening housing affordability. York: University of York. 


\section{Appendix A}

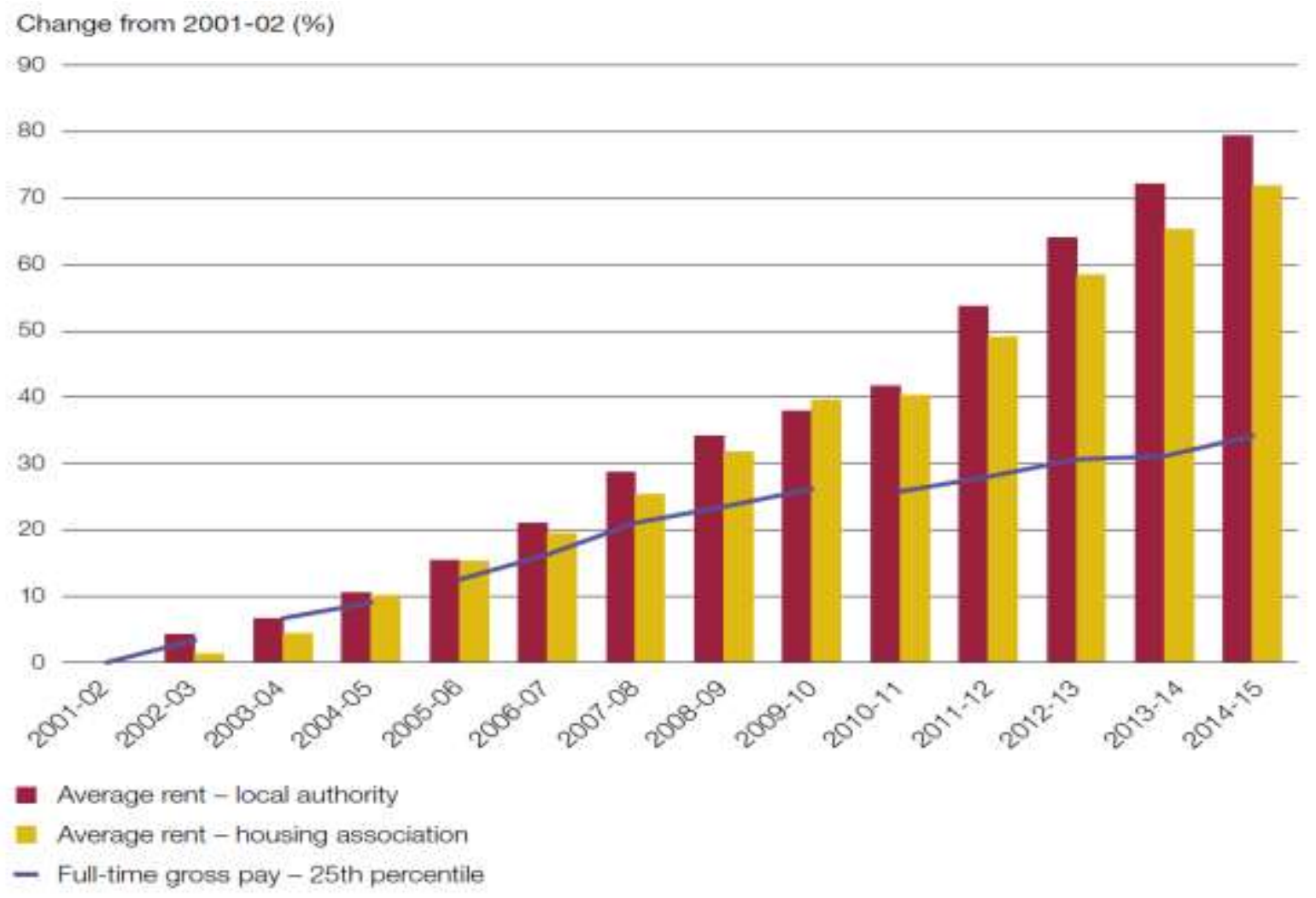

Appendix A: (National Audit Office, Housing in England: Overview, 2017) 


\section{Appendix B}

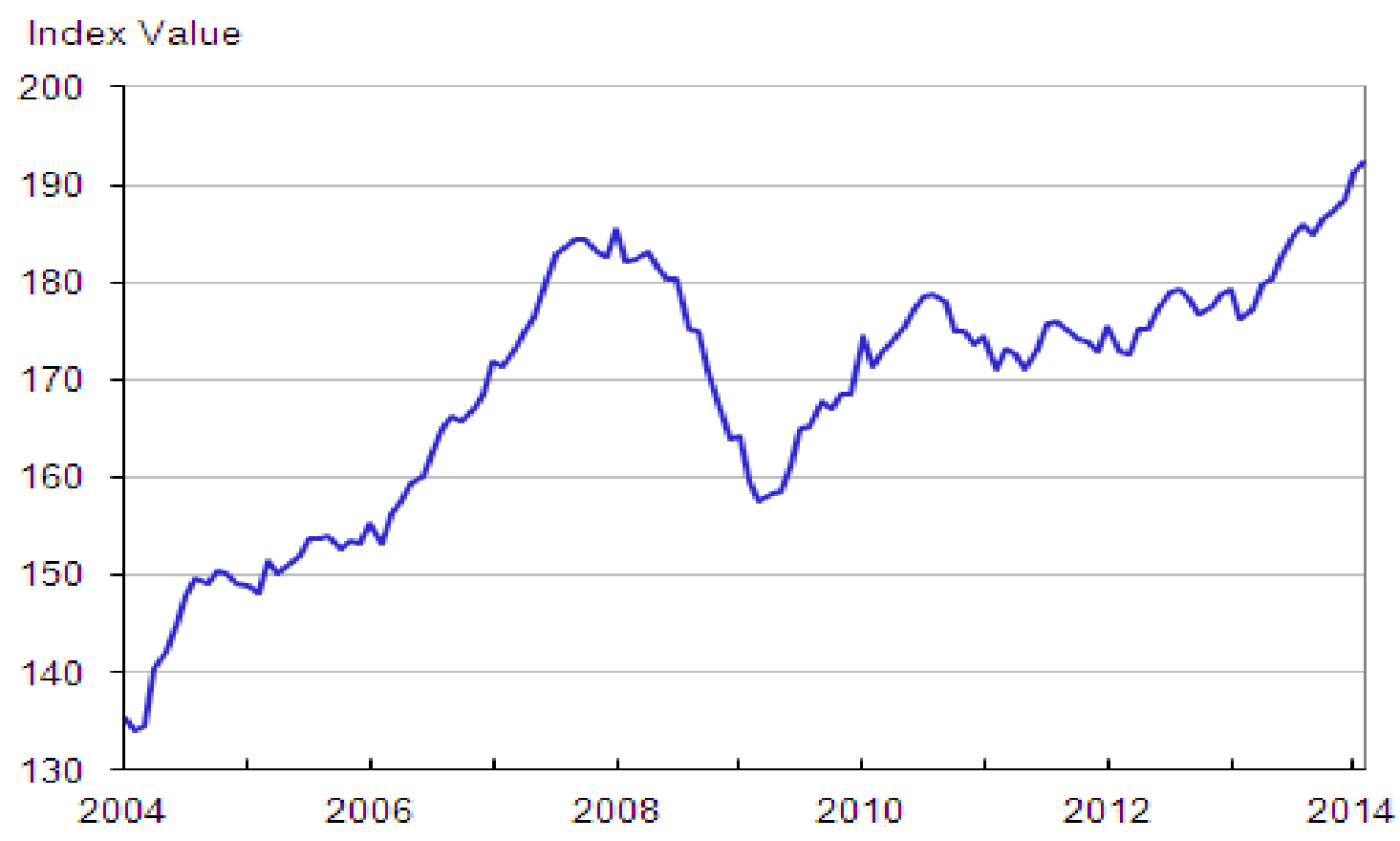

Appendix B: House Price Index in the UK (Office of National Statistics, 2014). 


\section{Appendix C}

\begin{tabular}{|c|c|c|}
\hline Interoperability Process (Research Adaptation) & $\begin{array}{l}\text { Study } \\
\text { Phases }\end{array}$ & Interoperability Tasks \\
\hline $\begin{array}{l}\text { Defines the scope and need for the development of } \\
\text { alternative solutions. }\end{array}$ & Phase 1 & $\begin{array}{l}\text { Establishment of the need of CLT } \\
\text { SEHM role in FTB homeownership. }\end{array}$ \\
\hline \multirow{2}{*}{$\begin{array}{l}\text { In order to generate a guide for financial interoperability } \\
\text { of the CLT SEHM with FTBs (end users). The research } \\
\text { investigated barrier sources hampering this synergy, hence } \\
\text { derived guides for assessment indicators and measures. }\end{array}$} & Phase 2 & $\begin{array}{l}\text { Identify barrier sources to FTB and } \\
\text { CLT SEHM financial } \\
\text { interoperability. }\end{array}$ \\
\hline & Phase 3 & $\begin{array}{l}\text { Derive assessment indicators and } \\
\text { measures through content analysis, } \\
\text { and a concept map for CLT SEHM } \\
\text { Interoperability issues associated } \\
\text { with FTB homeownership. }\end{array}$ \\
\hline $\begin{array}{l}\text { (Rationale for the selected approaches, and a summary of } \\
\text { alternatives considered). Generated indicators are } \\
\text { empirically validated to establish rationale for } \\
\text { interoperability factors to improve FTB and CLT SEHM } \\
\text { synergy in comparison to traditional alternatives. }\end{array}$ & Phase 4 & $\begin{array}{l}\text { Establish critical benchmark factors } \\
\text { and rationale for FTB and CLT } \\
\text { SEHM financial interoperability. }\end{array}$ \\
\hline
\end{tabular}

Appendix C: Interoperability Process 


\section{Appendix D}

Financial Interoperability:

FTB and CLT SEHM associated issues

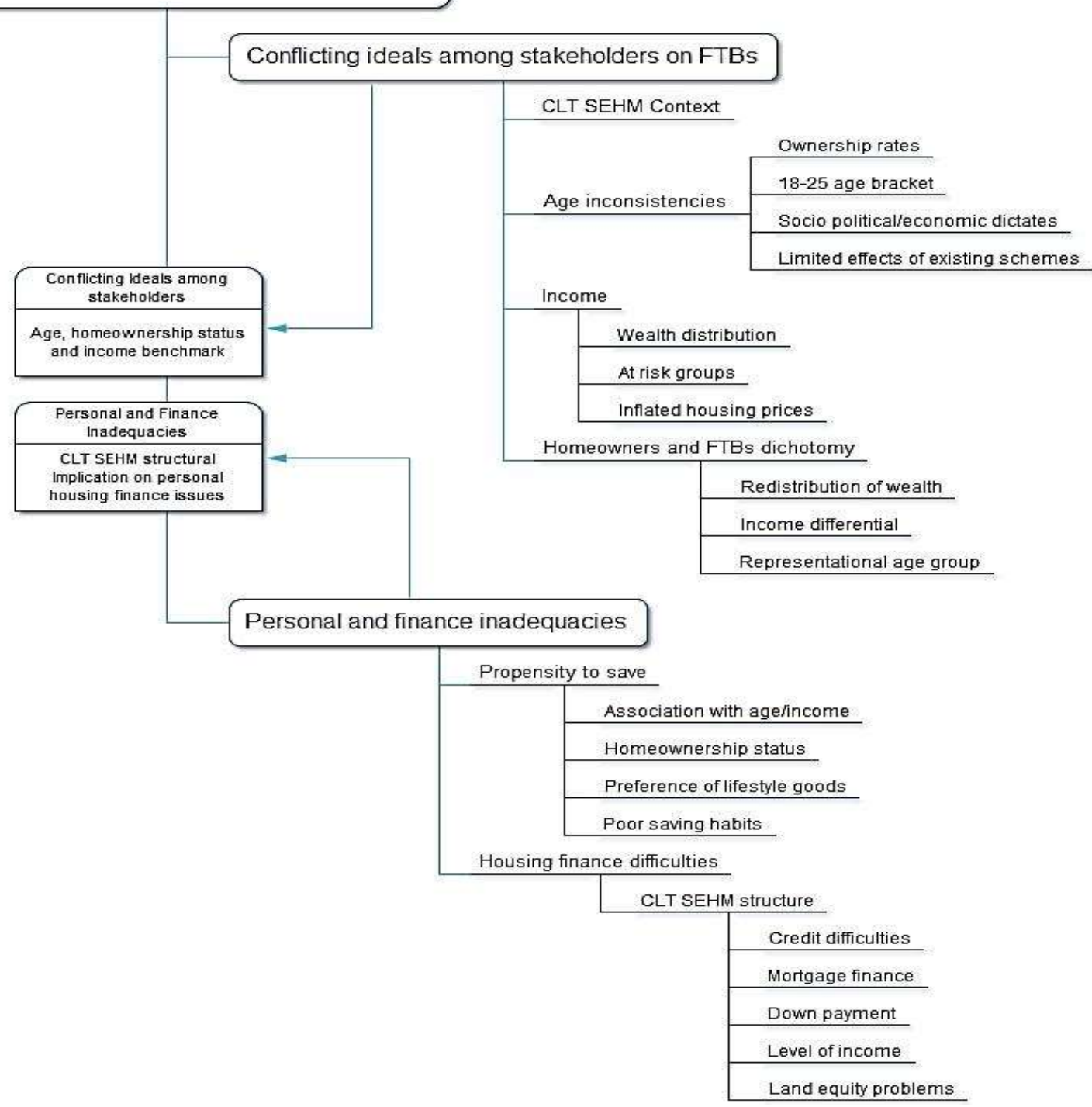

Appendix D: Concept map of associated issues: FTB and CLT SEHM financial interoperability 